\title{
Resenha
}

\section{Educação para o Pensar}

\author{
Education for Thinking \\ Educación para el pensamento
}

\author{
Flora Albuquerque Matos \\ Universidade Federal de Pernambuco
}

Certas perguntas sobre educação são difíceis responder, outras são quase impossíveis. Em seu livro mais recente, Deanna Kuhn, professora de Psicologia da Educação da Universidade Columbia - Nova lorque, não deixa de lado nenhuma delas. O livro aborda todo o seu projeto de pesquisa e é resultado de uma trajetória de mais de vinte anos de estudos empíricos, os quais permitiram à autora responder consistentemente qual é o principal propósito da Educação, assim como dissertar a respeito de quais habilidades são primordiais para o desenvolvimento cognitivo dos alunos.

Kuhn constrói a sua proposta relacionando diretamente objetivos educacionais e habilidades necessárias ao desenvolvimento dos estudantes. Por um lado, pressupõe que a escola não se justifica em si mesma, sendo uma instituição que faz alusão a um mundo além dela. A autora defende que a escola faz referência à vida dos estudantes e, por isso, o propósito central da Educação deve ser preparar os alunos para as demandas e oportunidades da vida. Por outro, argumenta que os diversos cenários da vida requerem que os estudantes sejam capazes de adquirir novos conhecimentos (aprender a conhecer), e tenham a capacidade de produzir suas próprias ideias a respeito de um tema (aprender a pensar). Finalmente, fechando essa relação entre escola e vida está a alegação de que essas habilidades não

Kuhn, D. (2005). Education for Thinking. Cambridge, MA: Harvard University Press.

surgem espontaneamente no percurso individual do desenvolvimento, fazendo-se necessária a intervenção escolar.

Partindo desses pressupostos, Kuhn propõe um direcionamento educacional intitulado Education for Thinking - termo que poderia ser traduzido como Educação para o Pensar. Sua proposta consiste em propor que a educação deve possibilitar que os estudantes aprendam a conhecer e a pensar, uma vez que essas habilidades são identificadas como primordiais para a vida. Especificamente, essas habilidades são, para Kuhn, a investigação e a argumentação.

A primeira parte do livro oferece um panorama geral da educação ao enumerar as expectativas da sociedade em relação aos frutos da escola e ao apresentar quatro propósitos educacionais usualmente defendidos - educação para instilar conhecimento, para desenvolver habilidades, para selecionar e para a cidadania -, os quais a autora avalia como insuficientes ou incompletos para atender àquelas expectativas.

Após se contrapor a esses propósitos, Kuhn apresenta duas escolas públicas da cidade de Nova lorque com realidades contrastantes que fornecerão as evidências empíricas para as discussões nos capítulos seguintes. A primeira, uma escola na região central da cidade frequentada principalmente por estudantes afro-americanos e his- 
pânicos, identificados pela autora como uma população em desvantagem ante a realidade social da cidade. A segunda se localiza no subúrbio, e seus estudantes têm pais com elevado nível de qualificação, caracterizados como uma população em vantagem.

As duas seções centrais do livro, a segunda e a terceira, observam a mesma sequência lógica e discorrem respectivamente sobre a investigação e a argumentação. Primeiro, Kuhn escreve que atividades de investigação e de argumentação já eram implementadas pelos professores das duas escolas analisadas. Apesar de apresentarem cenários sociais completamente diferentes, a autora observa que ambas as escolas não eram bem-sucedidas no oferecimento a alunos de atividades investigativas e argumentativas que correspondem ao nosso Ensino Fundamental II.

Em seguida, a autora discorre a respeito dos mecanismos psicológicos em jogo quando há o engajamento dos alunos nessas atividades. Segundo Kuhn, investigar consiste em coordenar teoria - conjunto de entendimentos prévios - e evidência - dado novo que tem o poder de confirmar ou negar o entendimento anterior. A autora explica que, se essa coordenação não for considerada, os alunos tenderão a usar os dados para reafirmar aquilo em que acreditam, pois reconhecer seu próprio pensamento como um dos possíveis e avaliá-lo ante a evidências é uma habilidade que precisa ser desenvolvida.

Argumentar também consiste em coordenar alguns fatores: além de articular informações externas e a própria perspectiva, o indivíduo precisa considerar ainda a perspectiva de outro. Nas escolas, a autora verificou que, ao se deparar com a perspectiva do outro, os estudantes, ou tomavam-na como sua própria, ou condicionavam-na à sua, muitas vezes distorcendo-a para confirmar o seu ponto de vista. Para o desenvolvimento das capacidades argumentativas, Kuhn afirma que em um diálogo é preciso que o indivíduo, além de defender o seu próprio ponto de vista, expondo-o e lançando argumentos para fortalecê-lo, também compreenda a perspectiva do outro e se utilize de contra-argumentos com o objetivo de enfraquecê-la.

Em terceiro lugar, essas seções se encerram com sugestões de atividades para o desenvolvimento de habilidades investigativas e argumentativas. Para a investigação, Kuhn propõe o trabalho com um modelo de causa e efeito, o qual possibilita confrontar os estudantes com dados que permitem a eles criar uma pergunta, testar variáveis e obter afirmações justificadas. Quanto à argumentação, Kuhn afirma que os professores tendem a construir modelos de debates em sala de aula nos quais os alunos se dirigem somente ao professor. Em contraposição a este tipo de manejo da argumentação, a autora propõe uma metodologia denominada argumentação dialógica, que enfatiza a importância de criar em sala de aula uma conversação autêntica, em que os alunos conversem uns com os outros e assim tirem de foco o professor.

Finalmente, o livro conclui com um panorama futuro, refletindo sobre o que significa ser uma pessoa educada. Ao focar o desenvolvimento das habilidades investigativas e argumentativas, Kuhn retira o foco das conquistas intelectuais já alcançadas por um estudante como um indicador de educação e aponta o potencial intelectual como uma medida mais coerente. Neste sentido, ser educado não se refere a quanto um estudante sabe a respeito de um tema, mas à habilidade de reconhecer o que outros pensaram a respeito do tópico e de produzir conhecimento por si mesmo.

De forma geral, a leitura do livro fornece ideias inspiradoras tanto para o trabalho em sala de aula quanto para o cenário educacional brasileiro. Mesmo descrevendo a realidade estadunidense, é possível uma identificação com os desafios educacionais apresentados e com as soluções encontradas, principalmente porque o relato ocorre sem exaltar ou menosprezar os contextos escolares: por um lado, uma escola com desafios de diversas ordens e, por outro, uma escola de excelência que não está isenta de problemas pedagógicos. O que Kuhn coloca em xeque é se há realmente uma distância significativa entre esses alunos em termos cognitivos. As evidências fornecidas pela autora sugerem que o foco no acúmulo de conhecimentos, visando à entrada nas melhores universidades, característica frequentemente encontrada nas escolas de excelência no Brasil, está longe de ser um propósito educacional suficiente e capaz de permitir o melhor desenvolvimento cognitivo dos alunos.

Apesar de o foco no acúmulo de conhecimentos ser um problema antigo, Kuhn não se restringe a identificá-lo, mas fundamenta sua oposição a esse modelo e se preocupa em apresentar um projeto educacional coerente com as suas reivindicações. Possibilitar que os estudantes se engajem em atividades de investigação e argumentação apresenta-se como uma proposta educacional pertinente porque, ao mesmo tempo possibilita o ensino de conteúdos escolares e permite que os alunos tenham papel ativo na construção de conhecimentos que se estendem para além do âmbito escolar.

Não obstante, Kuhn relata como, em ambas as escolas, professores bons e bem-intencionados muitas vezes falham em desenvolver em seus alunos habilidades investigativas e argumentativas. Apesar de o livro fornecer indícios de que um professor, dentro do seu planejamento de ensino, poderia administrar o desenvolvimento dessas habilidades sem mudanças curriculares grandiosas na escola, pode-se afirmar que o projeto demanda no mínimo um cuidadoso programa de formação de professores.

Um exemplo: a autora, após ter descrito o sucesso do modelo computacional de ensino por investigação idealizado por ela na escola em vantagem, relata como precisou adaptar esse modelo à outra escola, onde os alunos não viam o computador como uma ferramenta facilitadora. O computador foi substituído, então, por cartazes, e a atividade foi dividida em etapas dirigidas por monitores. Kuhn demonstra como essa adaptação foi pertinente à realidade dos estudantes, que obtiveram índices de desempenho completamente diferentes nas duas situações. A maneira como manejou a situação leva à reflexão sobre: a) como é possível utilizar outros recursos para a mesma atividade, mantendo-se o objetivo principal; b) como é necessário 
adaptar as atividades para um público específico; e c) como um modelo padrão de ensino não serve a todos os contextos, demandando pesquisa e preparação dos professores.

Apesar de não haver no livro um plano para formação de professores, é possível perceber que Kuhn demonstra uma constante preocupação com as implicações operacionais e pedagógicas da sua proposta. Não é uma tarefa fácil para um acadêmico transferir os avanços teóricos e conceituais da sua área de conhecimento para o emprego de práticas educacionais consistentes com a reflexão teórica, por isso o livro se constitui em uma real contribuição à Psicologia da Educação.

Em relação à teoria psicológica, Kuhn assume uma perspectiva interacionista a respeito do desenvolvimento humano. Logo na introdução do livro a autora se aproxima de uma visão exógena do desenvolvimento, quando concebe o pensamento como uma atividade social, distanciando-se do conceito de pensamento como algo individual e interno. Ao mesmo tempo, postula a existência de quatro níveis cognitivos - realistas, absolutista, relativista e avaliativo - que os alunos precisam percorrer em direção à compreensão epistemológica madura, o que a aproxima de uma visão endógena do desenvolvimento; porém não fica claro no livro como essas etapas cognitivas cronologicamente organizadas se conectam com a postulação de que o pensamento é uma atividade social.
Pelo nível de sofisticação teórica de todo o livro, é ingênuo acreditar que se trate de desconhecimento ou de inconsistência teórica. Kuhn está diante de um grande questionamento da Psicologia: por um lado, considera as particularidades de cada escola e sala de aula analisada, admitindo a cognição como dependente do contexto; por outro, postula a necessidade de pré-requisitos individuais para o sucesso das atividades, como a presença de valores intelectuais. Essa controvérsia não passa despercebida; a autora indica na conclusão que toma uma posição intermediária e controversa a respeito do debate sobre se as habilidades cognitivas são independentes ou dependentes do contexto, incentivando o desenvolvimento de mais pesquisas sobre o tema.

Apesar das controvérsias a respeito de como o desenvolvimento é constituído, a publicação de Kuhn vem favorecer o enriquecimento das discussões a respeito deste tema. Não é incomum encontrar propostas educacionais que incentivam a mudança curricular, propondo muitas vezes o foco na liberdade e no interesse dos estudantes, mas não especificam exatamente como essa mudança permitiria o efetivo desenvolvimento cognitivo dos alunos. O projeto Educação para o Pensar convence sobre a importância da investigação e da argumentação, habilidades vinculadas a uma maneira objetiva de formular ideias sobre o mundo que demandam para seu desenvolvimento atividades viáveis que estão de acordo com o histórico de práticas educacionais.

Recebido em: 25/09/2013

Reformulado em: 05/12/2013

Aprovado em: 30/12/2013

\section{Sobre a autora}

Flora Albuquerque Matos (floramatos@gmail.com)

Psicóloga e mestre em Psicologia Cognitiva pela Universidade Federal de Pernambuco (UFPE) 